\title{
MEASUREMENT UNCERTAINTY ANALYSIS OF THE STRAIN GAUGE BASED STABILOGRAPHIC PLATFORM
}

\author{
Wojciech WALENDZIUK ${ }^{*}$ \\ *Bialystok University of Technology, Faculty of Electrical Engineering, ul. Wiejska 45 D, 15-351 Bialystok, Poland \\ w.walendziuk@pb.edu.pl

\begin{abstract}
The present article describes constructing a stabilographic platform which records a standing patient's deflection from their point of balance. The constructed device is composed of a toughen glass slab propped with 4 force sensors. Power transducers are connected to the measurement system based on a 24-bit ADC transducer which acquires slight body movements of a patient. The data is then transferred to the computer in real time and data analysis is conducted. The article explains the principle of operation as well as the algorithm of measurement uncertainty for the COP (Centre of Pressure) surface $(\boldsymbol{x}, \boldsymbol{y})$.
\end{abstract}

Key words: Posturograph, Stabilography Center of Pressure, Measurement Uncertainty

\section{INTRODUCTION}

Posturography is an element of medical diagnostics and it has been used since 1970s. This type of examination supports a physician in diagnosing patient's balance system and enables distinction some factors which influence keeping balance. A basic balance test requires conducting a series of experiments during which a patient tries to keep his/her balance in a loose position with their eyes closed and opened. This type of examination is called Romberg's test (Cornilleau-Pérèsa et al., 2005; Soochan et al., 2012; Nashner, 1993). A patient standing on the platform tries to keep balance but, because of the balance system damage, he/she may sway in different directions or towards the damaged bony labyrinth. In this type of examination, using special platforms connected to computers becomes common. Data concerning the patient's posture stability is recorded in real time and then calculated as, e.g.: coordination coefficient, trajectory length, speed or deflection radius. Visualization of measurement results with the use of an appropriate program is the following stage of the procedure (Thurner et al., 2000; Dichgans et al., 1976). Interactive techniques are another form of conducting examination or rehabilitation. During such procedure, a patient reacts to certain information presented on a screen with his/her body stability. Such action enables establishing the time of response to a graphic or sound signal (Winter, 1990; Gage et al., 2004; Derlatka, 2012).

It is worth stressing that using computer measurement systems enabled graphic presentation of experiments results in the form of statokinesiogram. The image presented on the screen shows the movement trajectory of Centre of Pressure in the Cartesian system of coordinates. In the commonly used type of classification, the deflection from the $X$ axis is directed right and left, and the deflection along the $Y$ axis - forward and backward. Stabilography, which shows $\operatorname{COP}(x, y)$ coefficients in time, is another form of graphic presentation of measurement results (Baratto et al., 2004; Idzkowski, Walendziuk, 2009; Michalak, Jaskowski, 2002). The present article contains a description of a prototype device which performs those tasks. Additionally, the author conducted the analysis of metrological properties of the device using the measurement uncertainty technique (Joint Committee of Guides in Metrology, 2008). The use of this procedure enabled the assessment of the location accuracy of COP which is described by the $[x(i), y(i)]$ coefficients recorded during the platform being tested.

\section{STABILOGRAPHIC PLATFORM}

Stabilization of the vertical body position is done by minimizing its swaying in such a way that the vertical section of the body mass shifted beyond anatomical boundaries of the base of support located within the feet adhesion to the ground. Keeping stable vertical body position requires analysis of stimuli from sensor systems. Computerized dynamic posturography (CDP) is a test which helps record and assess postural reactions. This work presents a stabilographic platform which is based on 4 strain gauge sensors connected with a measurement data acquisition system.

\subsection{Data Acquisition Device}

The measurement system is composed of 3 functional modules. One of them is a measurement block based on strain gauge sensors and an analog-digital transducer (Fig.1). The measurement system is based on Wheatstone's bridges which contain strain gauge transducers measuring sensors deflection. The measurement signal is initially processed by operational amplifiers (MCP6N11) as coordinating systems, and low-pass filters. Then, specific voltages are sent to a 24-bit analogue-digital converter $\Sigma \Delta$ which communicates with another functional module with the use of Serial Peripheral Interface (SPI) acquiring data.

The data acquisition module on the prototype board equipped with an ARM type processor of the following parameters: $48 \mathrm{MHz}$ 
of maximum clock frequency, $128 \mathrm{~KB}$ Flash memory, $16 \mathrm{~KB}$ SRAM memory. The use of this system enables extending the device with an additional function, which is immediate visualization of measurement results.

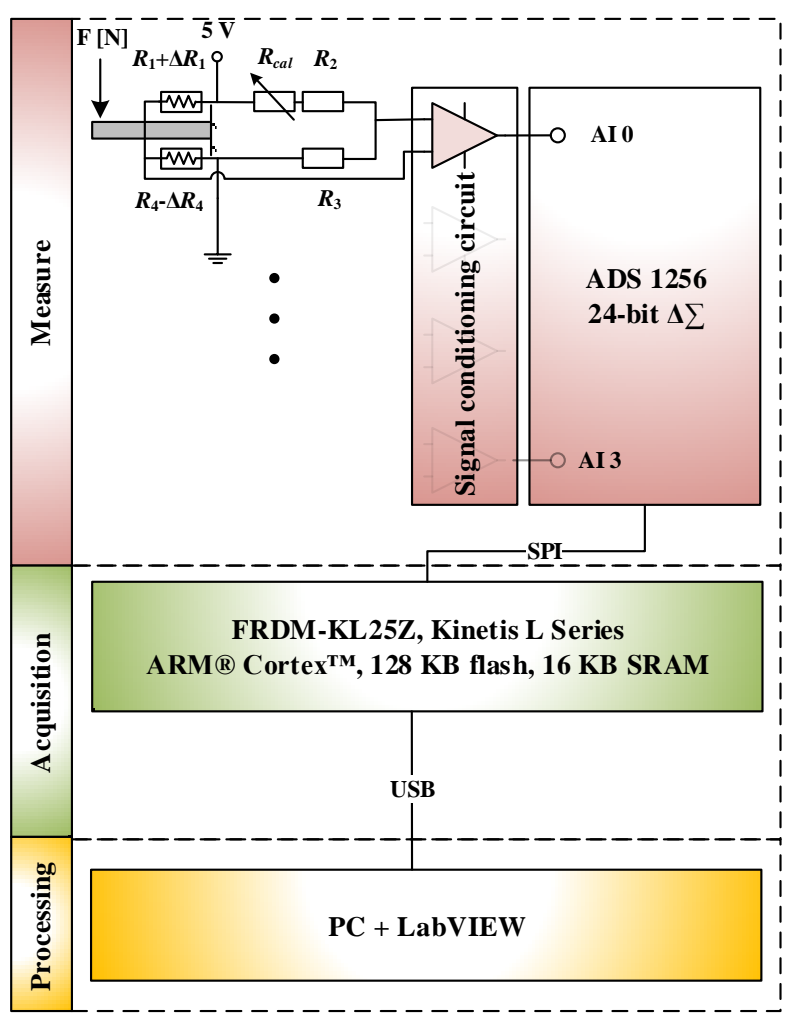

Fig. 1. Functional blocks of the measurement system

Because of the fact that the project in the beginning stage, it has been decided that measurement data is sent to the final functional block represented by a PC equipped with LabVIEW data acquisition and processing system. LabVIEW was used to create an application to visualize the trajectory of patient's centre of pressure (Fig. 2).

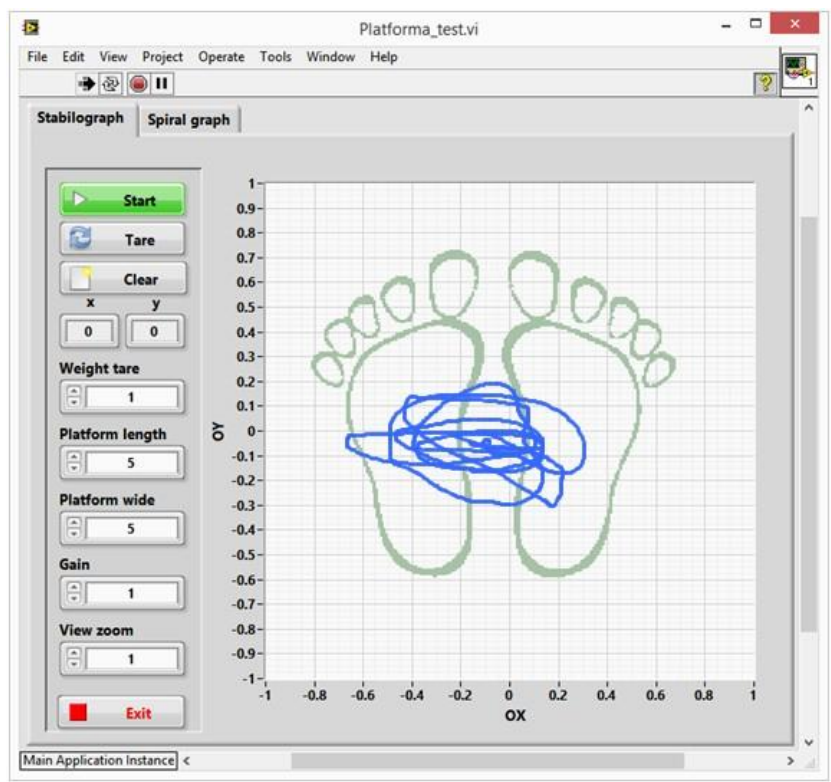

Fig. 2. Front panel view of the virtual instrument created in the LabVIEW system with registered trajectory
It is worth stressing that the device has been configured in a way which enables sending data through a USB interface or wirelessly with the use of devices operating in ZigBee standard.

\subsection{Platform Construction}

Rectangular platform made of safety tempered glass is the basic element of the device. The platform is embedded on 4 weight sensors placed in the corners of the slab. Each sensor is equipped with 2 resistance strain gauges of $120 \Omega$ and $k=2.15$ (Fig. 3). Considering forces denotations and the system of coordinates, equations of the centre of pressure point can be formed. The equations contain coefficients describing the force of pressure of individual sensors.

$$
\begin{aligned}
& x=\frac{L_{x}}{2}\left[1+\left(1+\frac{W_{t}}{\sum_{x=1}^{4} F_{x}}\right) \cdot \frac{F_{3}-F_{4}+F_{4}-F_{1}}{\sum_{x=1}^{4} F_{x}}\right]-\frac{L_{x}}{2} \\
& y=\frac{L_{y}}{2}\left[1+\left(1+\frac{W_{t}}{\sum_{x=1}^{4} F_{x}}\right) \cdot \frac{F_{3}-F_{2}+F_{4}+F_{1}}{\sum_{x=1}^{4} F_{x}}\right]-\frac{L_{y}}{2}
\end{aligned}
$$

where: $W_{t}-$ tare of the platform considering the weight of the platform, $F_{1}, F_{2}, F_{3}, F_{4}$ - forces influencing particular strain gauge sensors, $L_{x}, L_{y}$ - platform dimensions.

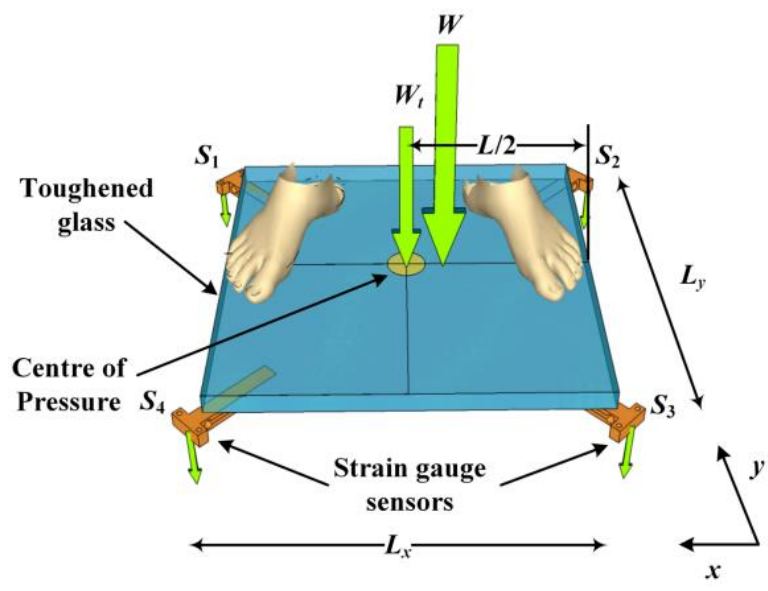

Fig. 3. General view of the platform with forces, sensors $S_{1}, S_{2}, S_{3}, S_{4}$ and coordinates assignation

Transducers in the system of the Wheatstone's bridge (Fig. 4) are connected in such a way that one of them is stretched and the other one - compressed. Thanks to this solution it is possible to obtain double amplification of the signal on the diagonal of the bridge.

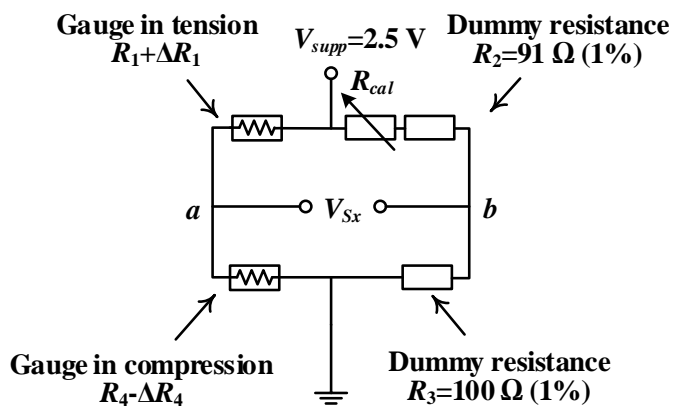

Fig. 4. Wheatstone's bridge circuit applied in the measurement sensor 
The equation describing the voltage $V_{S x}$ on the diagonal of the bridge can be formed with the use of the method of dividing the bridge system into voltage divisors and calculating the potential difference between the nodes ( $a$ and $b$ ). The following equation is formed:

$V_{a b}=V_{S x}=V_{\text {supp }} \cdot\left(\frac{R_{1}}{R_{1}+R_{4}}-\frac{R_{2}+R_{\text {cal }}}{R_{2}+R_{\text {cal }}+R_{3}}\right)$

A calibrating resistor was placed in the branch with a resistor of constant value of $R_{2}$. The resistor $R_{c a l}$ can have two aims. One of them is to equilibrate the bridge, which means - to help establish the value of the voltage $V_{S x}$ on the 0 level. The other task is enabling to implement offset voltage $V_{\text {offset }}$ in the system of the bridge. This solution enables a one-way system (pressure) to operate also two-way. Thanks to this, it is also possible to measure deflections in the opposite direction than the pressure direction, but with smaller resolution of the analog to digital converter (Fig. 5).

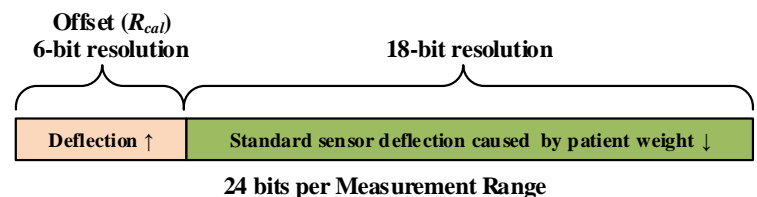

Fig. 5. Effective resolution range of analog to digital converter when calibration resistor is applied

However, the necessity of using a resistor of high precision, which is unfortunately difficult to do, is a disadvantage of the solution. In the presented measurement system a $20 \Omega$ multiturn trimmers resistor of $10 \%$ tolerance was used. Eventually, initial calibration of the measurement system was done by $R_{\text {cal }}$ resistor. The obtained $V_{S x}$ voltage was close to 0 level. The final version of the measurement equation takes the following form:

$V_{S x}=V_{\text {supp }} \cdot\left(\frac{R_{1}+\Delta R_{1}}{R_{1}+\Delta R_{1}+R_{4}-\Delta R_{4}}-\frac{R_{2}+R_{\text {cal }}}{R_{2}+R_{\text {cal }}+R_{3}}\right)$

Additionally, assuming that strain gauges have similar parameters and that they are placed centrically towards the measurement beam, it can be stated that their increments are equal $\Delta R_{1}=\Delta R_{4}=\Delta R$. the measurement equation can be then simplified to the following form:

$V_{S x}=V_{\text {supp }} \cdot\left(\frac{R_{1}+\Delta R}{R_{1}+R_{4}}-\frac{R_{2}+R_{\text {cal }}}{R_{2}+R_{\text {cal }}+R_{3}}\right)$

As the platform is equipped with 4 beams $\left(S_{1}, S_{2}, S_{3}, S_{4}\right)$, the above equation (5) can be applied to 4 voltages $\left(V_{S_{1}}, V_{S_{2}}, V_{S_{3}}\right.$, $V_{S_{4}}$ ) measured in systems based on Wheatstone's bridges. Measuring individual components enables establishing the centre of pressure of the platform COP according to equations (6) and (7):

$$
x=\frac{L_{x}}{2} \cdot\left[1+\left(1+\frac{V_{W t}}{V_{S_{1}}+V_{S_{2}}+V_{S_{3}}+V_{S_{4}}-V_{W t}}\right)\right.
$$

$$
y=\frac{L_{y}}{2} \cdot\left[1+\left(1+\frac{V_{W t}}{V_{S_{1}}+V_{S_{2}}+V_{S_{3}}+V_{S_{4}}-V_{W t}}\right)\right.
$$

where: $V_{W t}$ - tare of the device and offset voltages of the Wheatstone's bridge system, $V_{S_{1}}, V_{S_{2}}, V_{S_{3}}, V_{S_{4}}$ - values of voltage from the measurement sensors.

\section{ANALYSIS OF THE UNCERTAINTY OF MAXIMAL MEAS- UREMENT RESULTS}

The analysis of measurement uncertainty is based on calculating the maximum measurement error of the centre of pressure coefficients. This uncertainty depends on various factors, e.g. the supply voltage of the bridge system, resistance tolerance values, the accuracy of the analog to digital converter. Firstly, the coefficient of the influence of a given standard uncertainty on the total complex standard uncertainty must be evaluated. The law of uncertainty propagation must be applied in order to do it. On this basis, in order to calculate the value of measurement uncertainty, it is necessary to use the differential calculus in relation to the function of the equation describing indirect measurement. In this case partial differential equations for the function of processing the Wheatstone's bridge system should be formed, and then partial differential equations for the functions of calculating $x$ and $y$ coordinates.

\subsection{Uncertainty of Strain Gauge Measurement}

In the applied ADS1256 analog to digital converter, the manufacturer guarantees the 24-bits no missing codes measurement resolution for all data rates and internal programmable gain amplifier settings. Nevertheless, error factors such as nonlinearity $\pm 0.0010 \%$ or noise, which causes obtaining effective 23-bits noise-free resolution, should be taken into consideration. As the reference voltage equals $2.56 \mathrm{~V}$, maximum error of measurement

\begin{tabular}{|c|c|c|c|c|}
\hline $\begin{array}{l}\text { Error } \\
\text { source }\end{array}$ & $\begin{array}{l}\text { Error } \\
\text { measure }\end{array}$ & $\begin{array}{l}\text { Maximum } \\
\text { permissible } \\
\text { error value }\end{array}$ & $\begin{array}{l}\text { Distribu- } \\
\text { tion type }\end{array}$ & $\begin{array}{l}\text { Standard } \\
\text { uncertainty } \\
\text { of B type }\end{array}$ \\
\hline $\begin{array}{l}\text { Error } \\
\text { of voltage } \\
\text { measurement } \\
\text { conducted by } \\
\text { ADC }\end{array}$ & $\begin{array}{l}V_{\text {supp }} \\
=2.5 \mathrm{~V} \\
\pm 0.001 \%\end{array}$ & $25.00 \mu \mathrm{V}$ & rectangular & $\begin{array}{l}\frac{25.00 \mu \mathrm{V}}{\sqrt{3}} \\
=14.43 \mu \mathrm{V}\end{array}$ \\
\hline $\begin{array}{l}R_{2} \text { resistance } \\
\text { tolerance }\end{array}$ & $\begin{array}{l}R_{2} \\
=91 \Omega \\
\pm 1 \%\end{array}$ & $0.91 \Omega$ & rectangular & $\begin{array}{l}\frac{0.91 \Omega}{\sqrt{3}} \\
=0.53 \Omega\end{array}$ \\
\hline $\begin{array}{l}R_{3} \text { resistance } \\
\text { tolerance }\end{array}$ & $\begin{array}{l}R_{3} \\
=100 \Omega \\
\pm 1 \%\end{array}$ & $1.00 \Omega$ & rectangular & $\begin{array}{l}\frac{1.00 \Omega}{\sqrt{3}} \\
=0.58 \Omega\end{array}$ \\
\hline $\begin{array}{l}R_{\text {cal }} \text { resistor } \\
\text { tolerance } \\
\text { for maximum } \\
\text { value } \\
\text { of resistance }\end{array}$ & $\begin{array}{l}R_{\text {cal }}(\max ) \\
=20 \Omega \\
\pm 10 \%\end{array}$ & $2.00 \Omega$ & rectangular & $\begin{array}{l}\frac{2.00 \Omega}{\sqrt{3}} \\
=1.54 \Omega\end{array}$ \\
\hline $\begin{array}{l}\text { Maximal error } \\
\text { of } R_{1} \text { strain } \\
\text { gauges }\end{array}$ & $\begin{array}{l}\text { determined } \\
\text { during } \\
\text { experiment }\end{array}$ & $5.66 \mathrm{~m} \Omega$ & normal & $5.66 \mathrm{~m} \Omega$ \\
\hline $\begin{array}{l}\text { Maximal error } \\
\text { of } R_{4} \text { strain } \\
\text { gauges }\end{array}$ & $\begin{array}{l}\text { determined } \\
\text { during } \\
\text { experiment }\end{array}$ & $4.57 \mathrm{~m} \Omega$ & normal & $4.57 \mathrm{~m} \Omega$ \\
\hline
\end{tabular}
conducted by a transducer will not exceed $25.60 \mu \mathrm{V}$.

Tab. 1 Maximum permissible errors values of the elements of the measurement system 
Maximum permissible error values of transducers and the other resistances in the system are additional factors. Maximal error of force transducers were established in a measurement experiment. Maximal errors were measured for 4 applied transducers placed on the surface of the beam and underneath it. Their biggest values were selected for the purpose of calculations. Other maximum permissible errors and the values of standard uncertainty are presented in Tab. 1.

Equation (8), concerning standard uncertainty, was formed on the basis of the expression describing voltage on diagonals of the bridge. After determining partial derivatives towards particular variables, equations $(9-14)$ were obtained.

$$
\begin{gathered}
u^{2}\left(V_{S x}\right)=\left(\frac{\partial V_{S x}}{\partial V_{\text {supp }}}\right)^{2} \cdot u^{2}\left(V_{\text {supp }}\right)+\left(\frac{\partial V_{S x}}{\partial R_{1}}\right)^{2} \cdot u^{2}\left(R_{1}\right) \\
+\left(\frac{\partial V_{S x}}{\partial R_{2}}\right)^{2} \cdot u^{2}\left(R_{2}\right)+\left(\frac{\partial V_{S x}}{\partial R_{3}}\right)^{2} \\
\cdot u^{2}\left(R_{3}\right)+\left(\frac{\partial V_{S x}}{\partial R_{4}}\right)^{2} \cdot u^{2}\left(R_{4}\right) \\
+\left(\frac{\partial V_{S x}}{\partial R_{\text {cal }}}\right)^{2} \cdot u^{2}\left(R_{\text {cal }}\right) \\
\left(\frac{\partial V_{S x}}{\partial V_{\text {supp }}}\right)^{2}=\left(-\frac{\left(R_{2}+R_{\text {cal }}\right) \cdot R_{4}-R_{1} \cdot R_{3}}{\left(R_{2}+R_{3}+R_{\text {cal }}\right) \cdot\left(R_{4}+R_{1}\right)}\right)^{2} \\
\left(\frac{\partial V_{S x}}{\partial R_{1}}\right)^{2}=\left(-\frac{V_{\text {supp }} \cdot R_{4}}{\left(R_{4}+R_{1}\right)^{2}}\right)^{2}=8.257 \cdot 10^{-10} \frac{\mathrm{V}^{2}}{\Omega^{2}} \\
\left(\frac{\partial V_{S x}}{\partial R_{2}}\right)^{2}=\left(-\frac{V_{\text {supp }} \cdot R_{3}}{\left(R_{3}+R_{2}+R_{\text {cal }}\right)^{2}}\right)^{2}=0.526 \cdot 10^{-5} \frac{\mathrm{V}^{2}}{\Omega^{2}} \\
\left(\frac{\partial V_{S x}}{\partial R_{3}}\right)^{2}=\left(-\frac{V_{\text {supp }} \cdot\left(R_{2}+R_{\text {cal }}\right)}{\left(R_{3}+R_{2}+R_{\text {cal }}\right)^{2}}\right)^{2}=1.241 \cdot 10^{-5} \frac{\mathrm{V}^{2}}{\Omega^{2}} \\
\left(\frac{\partial V_{S x}}{\partial R_{4}}\right)^{2}=\left(-\frac{V_{\text {supp }} \cdot R_{1}}{\left(R_{4}+R_{1}\right)^{2}}\right)^{2}=9.468 \cdot 10^{-10} \frac{\mathrm{V}^{2}}{\Omega^{2}} \\
\left(-\frac{V_{\text {supp }} \cdot R_{3}}{\left(R_{3}+R_{2}+R_{\text {cal }}\right)^{2}}\right)^{2}=4.439 \cdot 10^{-5} \frac{\mathrm{V}^{2}}{\Omega^{2}}
\end{gathered}
$$

Eventually, after substituting the data, standard uncertainty of voltage measurement of the following value was obtained:

$u\left(V_{S x}\right)=7.878 \cdot 10^{-3} \mathrm{~V}$

\subsection{Uncertainty of Coordinates Calculation}

In order to determine standard uncertainty of the centre of pressure $x$ coordinate, partial differential equations for equation (6) were formed.

$$
\begin{aligned}
u^{2}(x)=\left(\frac{\partial x}{\partial L_{x}}\right)^{2} \cdot & u^{2}\left(L_{x}\right)+\left(\frac{\partial x}{\partial V_{W t}}\right)^{2} \cdot u^{2}\left(V_{W t}\right) \\
& +\left(\frac{\partial x}{\partial V_{S 1}}\right)^{2} \cdot u^{2}\left(V_{S 1}\right)+\left(\frac{\partial x}{\partial V_{S 2}}\right)^{2} \\
& \cdot u^{2}\left(V_{S 2}\right)+\left(\frac{\partial x}{\partial V_{S 3}}\right)^{2} \cdot u^{2}\left(V_{S 3}\right) \\
& +\left(\frac{\partial x}{\partial V_{S 4}}\right)^{2} \cdot u^{2}\left(V_{S 4}\right)
\end{aligned}
$$

The following data were taken in order to conduct the computations: the width of the platform - $L_{x}=0.251 \mathrm{~m}$, determined with the use of a Leica DISTO D3a distance meter of the accuracy which equaled $\pm 1 \mathrm{~mm}$, the value of numerical tarring (in the program algorithm) the platform with no load $W_{t}=0.000 \mathrm{~V}$, uncertainty values of voltage measurement in Wheatstone's bridge $\left(V_{S_{1}}, V_{S_{2}}, V_{S_{3}}, V_{S_{4}}\right)=7.878 \cdot 10^{-3} \mathrm{~V}$. Final values of partial differential equations $(17-22)$ :

$$
\begin{gathered}
\left(\frac{\partial x}{\partial L_{x}}\right)^{2}=\left(\frac{V_{S_{4}}-V_{S_{3}}-V_{S_{2}}+V_{S_{1}}}{2 \cdot\left(V_{W t}-V_{S_{1}}-V_{S_{2}}-V_{S_{3}}-V_{S_{4}}\right)}\right)^{2} \\
=0.000 \frac{\mathrm{V}^{2}}{\mathrm{~V}^{2}} \\
\left(\frac{\partial x}{\partial V_{W t}}\right)^{2}=\left(\frac{-L_{x} \cdot\left(V_{S_{4}}-V_{S_{3}}-V_{S_{2}}+V_{S_{1}}\right)}{2 \cdot\left(V_{W t}-V_{S_{1}}-V_{S_{2}}-V_{S_{3}}-V_{S_{4}}\right)^{2}}\right)^{2} \\
=0.000 \frac{\mathrm{m}^{2}}{\mathrm{~V}^{2}} \\
\left(\frac{\partial x}{\partial V_{S_{1}}}\right)^{2}=\left(\frac{L_{x} \cdot\left(V_{W t}-2 \cdot V_{S_{2}}-2 \cdot V_{S_{3}}\right)}{2 \cdot\left(V_{W t}-V_{S_{1}}-V_{S_{2}}-V_{S_{3}}-V_{S_{4}}\right)^{2}}\right)^{2} \\
=15.861 \frac{\mathrm{m}^{2}}{\mathrm{~V}^{2}}
\end{gathered}
$$

$$
\begin{gathered}
\left(\frac{\partial x}{\partial V_{S_{2}}}\right)^{2}=\left(\frac{-L_{x} \cdot\left(V_{W t}-2 \cdot V_{S_{1}}-2 \cdot V_{S_{4}}\right)}{2 \cdot\left(V_{W t}-V_{S_{1}}-V_{S_{2}}-V_{S_{3}}-V_{S_{4}}\right)^{2}}\right)^{2} \\
=15.861 \frac{\mathrm{m}^{2}}{\mathrm{~V}^{2}}
\end{gathered}
$$

$$
\begin{gathered}
\left(\frac{\partial x}{\partial V_{S_{3}}}\right)^{2}=\left(\frac{-L_{x} \cdot\left(V_{W t}-2 \cdot V_{S_{1}}-2 \cdot V_{S_{4}}\right)}{2 \cdot\left(V_{W t}-V_{S_{1}}-V_{S_{2}}-V_{S_{3}}-V_{S_{4}}\right)^{2}}\right)^{2} \\
=15.861 \frac{\mathrm{m}^{2}}{\mathrm{~V}^{2}} \\
\left(\frac{\partial x}{\partial V_{S_{4}}}\right)^{2}=\left(\frac{L_{x} \cdot\left(V_{W t}-2 \cdot V_{S_{2}}-2 \cdot V_{S_{3}}\right)}{2 \cdot\left(V_{W t}-V_{S_{1}}-V_{S_{2}}-V_{S_{3}}-V_{S_{4}}\right)^{2}}\right)^{2} \\
=15.861 \frac{\mathrm{m}^{2}}{\mathrm{~V}^{2}}
\end{gathered}
$$

On the basis of solution equation (16), uncertainty value of the $x$ coordinate was obtained:

$u^{2}(x)=0.0627 \mathrm{~m}$

Calculating the uncertainty of the standard $y$ coordinate is the following stage of the process. With the use of the differential calculus for equation (7), equation (24) was obtained:

$$
\begin{aligned}
u^{2}(y)=\left(\frac{\partial y}{\partial L_{y}}\right)^{2} \cdot & u^{2}\left(L_{y}\right)+\left(\frac{\partial y}{\partial V_{W t}}\right)^{2} \cdot u^{2}\left(V_{W t}\right) \\
& +\left(\frac{\partial y}{\partial V_{S 1}}\right)^{2} \cdot u^{2}\left(V_{S 1}\right)+\left(\frac{\partial y}{\partial V_{S 2}}\right)^{2} \\
& \cdot u^{2}\left(V_{S 2}\right)+\left(\frac{\partial y}{\partial V_{S 3}}\right)^{2} \cdot u^{2}\left(V_{S 3}\right) \\
& +\left(\frac{\partial y}{\partial V_{S 4}}\right)^{2} \cdot u^{2}\left(V_{S 4}\right)
\end{aligned}
$$


Next, after substituting data: the length of the platform (measured - as in the previous case - by a laser device for distance measurement) $L_{y}=0.252 \mathrm{~m}$, the tare value with no load $V_{W t}=0.000 \mathrm{~V}$, values of voltage measurement uncertainty in Wheatstone's bridges $\left(V_{S_{1}}, V_{S_{2}}, V_{S_{3}}, V_{S_{4}}\right)=7.878 \cdot 10^{-3} \mathrm{~V}$, in equations $(25-30)$, (31) was obtained.

$$
\begin{gathered}
\left(\frac{\partial y}{\partial L_{y}}\right)^{2}=\left(\frac{V_{S_{1}}+V_{S_{2}}-V_{S_{3}}-V_{S_{4}}}{2 \cdot\left(V_{W t}-V_{S_{1}}-V_{S_{2}}-V_{S_{3}}-V_{S_{4}}\right)}\right)^{2} \\
=0.000 \frac{\mathrm{V}^{2}}{\mathrm{~V}^{2}}
\end{gathered}
$$

$$
\begin{gathered}
\left(\frac{\partial y}{\partial V_{W t}}\right)^{2}=\left(\frac{L_{y} \cdot\left(-V_{S_{1}}-V_{S_{2}}+V_{S_{3}}+V_{S_{4}}\right)}{2 \cdot\left(V_{W t}-V_{S_{1}}-V_{S_{2}}-V_{S_{3}}-V_{S_{4}}\right)^{2}}\right)^{2} \\
=0.000 \frac{\mathrm{V}^{2}}{\mathrm{~V}^{2}}
\end{gathered}
$$

$$
\begin{gathered}
\left(\frac{\partial y}{\partial V_{S_{1}}}\right)^{2}=\left(\frac{L_{y} \cdot\left(V_{W t}-2 \cdot V_{S_{3}}-2 \cdot V_{S_{4}}\right)}{2 \cdot\left(V_{W t}-V_{S_{1}}-V_{S_{2}}-V_{S_{3}}-V_{S_{4}}\right)^{2}}\right)^{2} \\
=15.988 \frac{\mathrm{m}^{2}}{\mathrm{~V}^{2}}
\end{gathered}
$$

$u^{2}(y)=0.0630 \mathrm{~m}$

\section{CONCLUSIONS}

This work presents the results of the measurement uncertainty computations of a stabilographic platform centre of pressure. Identical maximal errors of strain gauges were assumed in calculations. The errors were determined experimentally, examining each sensor individually. Then, maximum error values (for strain gauges placed on the upper and lower parts of the beam) ob- tained for $S_{3}$ sensor were chosen for computations. It appeared that sensor $S_{3}$ was the most precise and it introduced the biggest measurement error into the platform system.

The results of the determined standard uncertainty for $x$ and $y$ coordinates are similar and equal about $63 \mathrm{~mm}$, which is a relatively big value. However, this value was determined for maximum error values of particular parts of the measurement system.

Analysis of measurement repetitiveness, as well as examining the centre of pressure alignment of the platform will be the following stage of the research.

\section{REFERENCES}

1. Baratto M., Cervera Ch., Jacono M. (2004), Analysis of Adequacy of a Force Platform for Stabilometric Clinical Investigations, Mediterranean Conference on Measurement, 207-211.

2. Cornilleau-Pérèsa V., Shabanac N., Droulezd J., Gohe J.C.H., Leef G.S.M., Chew P.T.K. (2005), Measurement of the Visual Contribution to postural steadiness from the COP Movement: Methodology And Reliability, Gait \& Posture, Vol. 22, 2, 96-106.

3. Derlatka M. (2012), Human Gait Recognition Based on Signals from Two Force Plates, Lecture Notes in Computer Science, Vol. 7268: Artificial Intelligence and Soft Computing, Springer-Verlag, 251-258.

4. Dichgans J., Mauritz K.H., Allum J.H.J., Brandt T. (1976), Postural Sway in Normals and Ataxic Patients: Analysis of the Stabilizing and Destabilizing Effects of Vision, Agressologie, 17, 15-24.

5. Evaluation of Measurement Data - Guide to the Expression of Uncertainty in Measurement, JCGM (Joint Committee of Guides in Metrology) (2008).

6. Gage W.H., Winter D.A., Frank J.S., Adkin A.L. (2004), Kinematic and Kinetic Validity of the Inverted Pendulum Model in Quiet Standing, Gait Posture 19, 124-132.

7. Idzkowski A., Walendziuk W., (2009), Evaluation of the Static Posturograph Platform Accuracy, Journal of Vibroengineering, Vol. 11, 3, 511-516.

8. Michalak K., Jaskowski P. (2002), Dimensional Complexity of Posturographic Signals: I.Optimization of Frequency Sampling and Recording Time, Curr Topics in Biophys, 26(2), 235-244.

9. Nashner L.M. (1993), Computerized Dynamic Posturography in G. P. Jacobsen; C. W. Newman; and J. M. Kartush (eds.), Handbook of Balance Function Testing, Mosby-Year Book: Chicago, IL, 309-323.

10. Soochan K., Mijoo K. Nambom K., Sungmin K., Gyucheol H., (2012), Quantification and Validity of Modified Romberg Tests Using Three-Axis Accelerometers, Green and Smart Technology with Sensor Applications, Communications in Computer and Information Science, Vol. 338, 254-261.

11. Thurner S., Mittermaier C., Hanel R., Ehrenberger K. (2000), Scaling violation phenomena and fractality in the Human Posture Control System, Physical Review E, 62(3).

12. Winter D.A. (1990), Biomechanics and Motor Control of Human Movement, John Wiley \& Sons Inc., Toronto.

The work has been accomplished under the research project No. S/WE/1/2013. 